6.5 per cent.; one eosinophilic small Iymphocyte was seen; eosinophiles, 6.5 per cent.; no transitionals. The red blood cells from the left arm were crenated.

This is a case which resembles elephantiasis very closely, and by some would be classed under that heading, but because of the following reasons I have classed it under elephantoid dystrophy.

1. The dystrophy is congenital and affects both the arm and the leg on the same side. In elephantiasis usually only one nember is affected.

2. An inguinal hernia is present on the left side.

3. A mole is present on the left side of the face.

4. The tongue and right side of the face are both en-

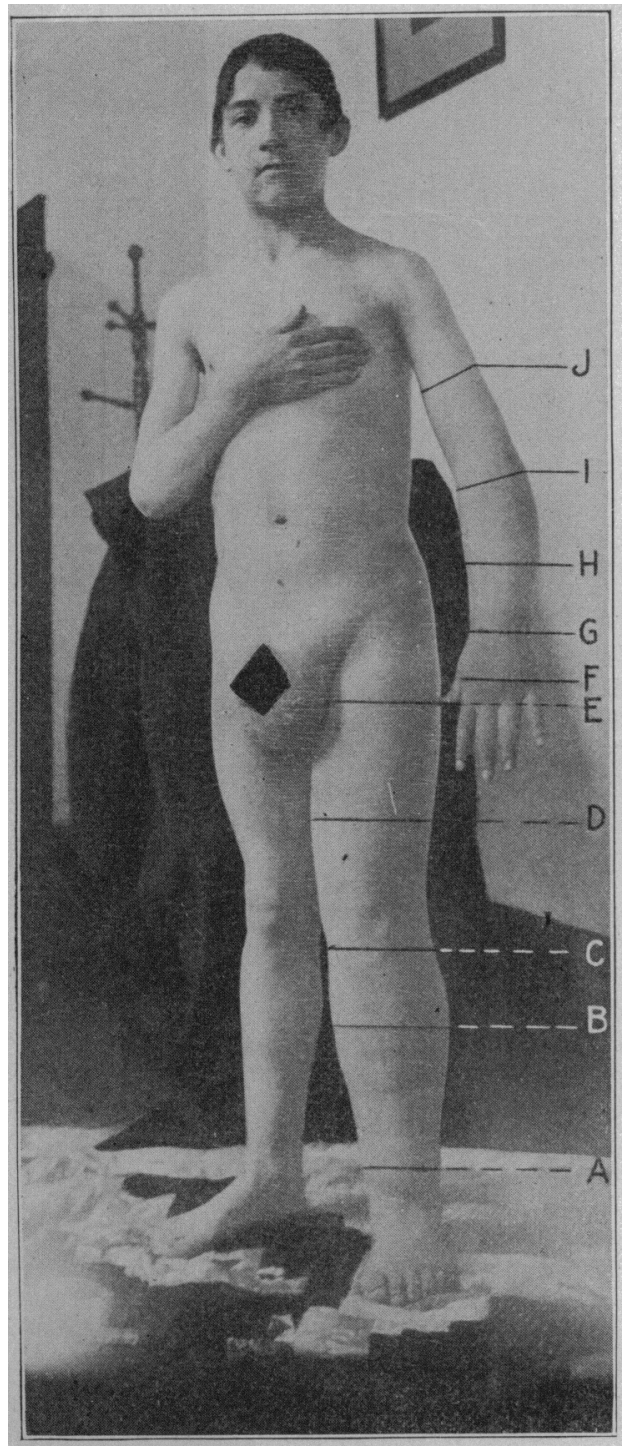

Photograph shows how much larger the left arm and leg are than the corresponding members on the opposite side. It also shows the mole which is present on the left side of the face and the difference in size between the right and left side, the right side the diference in size between the right and left side, the right side belng the larger. The enlarged scrotum and the hernia are also to $14 ; \mathrm{B}-\mathrm{R}, 13$, L. 20: C-R, 131/4, L. 17\%; $\mathrm{D}-\mathrm{R}, 173 / \mathrm{4}$, L. 21\%

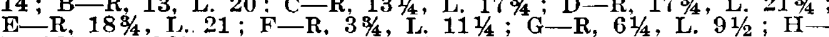

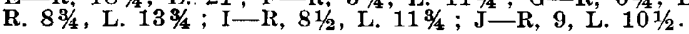

larged. The last three conditions indicate a congenital maldevelopment, and without doubt-it seems to methe lymphatics of the affected limb are also in some way changed so that they are less permeable for the lymph stream.

All of these show the undoubted congenital origin, with the possibility of congenital lymphatic change.

\section{SUCTION MASSAGE OF THE EARS.}

\author{
MAURY M. STAPLER, M.D. \\ Aurist to Macon City Hospital. \\ MACON, GA.
}

The instrument here described is for the purpose of manipulating and treating all the structures of the ear. It is in full accord with the pathologic requirements and latest scientific teaching. It is not offered to the profession as a "cure all," but rather as an advance over Politzer's method and the use of the hard rubber catheter. It is a safe palliative treatment to be used instead of an unsafe irritative one. As may be seen by the illustration, the instrument has five connecting branches of soft rubber tubing to which may be affixed a rubber air bag having hard rubber valves through which suction or inflation may be practiced.

The tips of the two longest branches should close the ears and should be held by the patient. Two shorter ones should close the nostrils of the patient and should be held lightly in the nose by the left hand of the operator. The bag is affixed to the remaining branch.

The patient should be instructed how to close the pharynx by holding the breath with the cheeks inflated full. (Do not blow through the nose.) Some patients succeed better by making the sound ah or by swallowing, and children close the pharynx when crying.

Suction should first be made to cleanse the tubes and

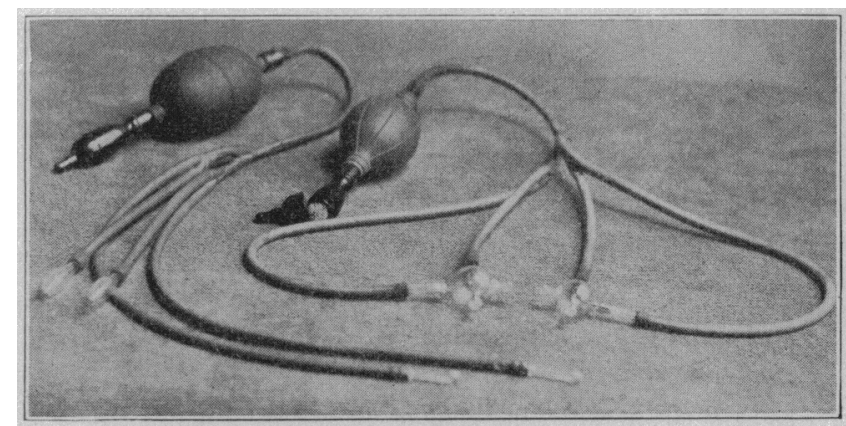

Suction apparatus for ear massage, with glass models of the ears at tached.

accessory cavities of the head, i. e., middle ears, frontal, sphenoid, ethmoid, and maxillary sinuses; to cause artificial hyperemia; to move all the movable structures of the ears, thereby breaking adhesions and giving a thorough massage.

The air bag should be held in the right hand of the operator and suction made in the usual way. Inflation should follow to dilate the Eustachian tubes and to reestablish the air pressure in the cavities. This may be done by attaching the inflation end of the air bag which contains a sponge or by attaching a compressed-air apparatus to the rubber tubing. Medication may be given at the same time from a sponge in the hard rubber medicator or from compressed air medicators. The ears are being properly reached only when the alæ of the nose are drawn down during suction and distended by inflation. The operator should then remove the instrument and with the palms of his hands tightly cover the patient's ears and pull the head upward strongly.

The special claims for the instrument are: It obviates the danger of blowing infected mucus into a closed cavity- the middle ear; it draws such matter away into the throat; it does not stretch the tympanic membranes, they are held passive in a rarefied or compressed atmosphere; it produces artificial hyperemia at the seat of the 
disease, as cupping would produce artificial hyperemia in any other part of the body; it offers an effective, safe, and pleasant treatment of the ears.

The illustration shows two glass models of the ears attached to the instrument, by pressing the air bag and watching the movement of straws representing the ossicular chain and cotton representing the tympanic membranes and covering of the oval windows, the most important claims stated may be demonstrated to the eves. By using Seigel's speculum the tympanic membrane may be scen to make an excursion outward, and when the membrane has been removed and a movable stapes lias been left in position this bone has been observed to make a similar excursion outward. The conclusion is drawn, therefore, that removal of the air externally and internally from the ear causes an outward movement of the ossicular chain and tympanic membranes independently of any pulling on these membranes. A most important consideration, if true.

In some of the hospitals of Germany and Austria, some months ago, questions were raised, clinical material furnished and valuable assistance given to prove or disprove whatever was not clear in this method. For example:

1. It was questioned whether or not the Eustachian tubes would collapse under the suction as do the alæ of the nose, and it was decided that they would not, because the air is removed externally to their openings and there is no pressure to close them as in the case of the nose, which is subjected to the influence of the external atmosphere.

2 . It was questioned whether or not, clinically, the stapes would move as was shown on the model, and this was satisfactorily proved bv the use of Seigel's speculum in a case in which the membrane and the other two bones-malleus and incus-of the ossicular chain had been lost, leaving a movable stapes and open Eustachian tube.

3 . It was questioned whether or not strong suction would prove dangerous, and suction was made with a strong pump until the nose bled; the hearing registered the same as before, and the patient had no pain of the ears, but some of the frontal sinus.

4. Its effects were tested on a patient with the Eustachian tubes tightly closed, and it was found that the suction gave comfort; inflation gave pain, because, the air being rarefied in the middle ears, suction relieved the pressure from without and inflation added thereto.

5 . It was questioned whether or not the secretions would be drawn from the middle ears, so the nose and pharynx were cleansed thoroughly, and after suction mucus was seen flowing from the Eustachian tubes and frontal sinus.

6. It was questioned whether or not this method would relieve pain in acute cases; in some it did, in others it did not; but no reason could be given.

7. Tests were made to decide whether or not this procedure would benefit the hearing in hypertrophic conditions and improvement was claimed in every case.

8. The method was thought beneficial also in three atrophic cases and the results were attributed to artificial hyperemia. Good results were not obtained in two cases of disease of the auditory nerve.

I suggested to Professor Alexander, who is in charge of Professor Politzer's clinic in Vienna, that the medical profession might like to have an expression of opinion from him on the subject. and he replied in the presence of his class: "Tell them it is good, good, very good." I have a written indorsement from him also. We know that error long established takes on the garb of truth and he who essays to dislodge it has set himself a life work; nevertheless, I present this method to the members of the profession, believing that their discriminating common sense will prefer it to Politzer's method.

Acknowledgments are due to Dr. John B. McMahon of New York City for his valuable assistance rendered me in the hospitals of Germany.

\section{STRUCTURAL CHANGES AND SURVIVAL OF CELLS IN TRANSPLANTED BLOOD VESSELS.}

C. C. GUTHRIE, Ph.D., M.D.

Professor of Physiology, Washington University Međical School. ST. LOUIS.

When blood ressels, e. g., the carotid arteries, are anastomosed end to end, in situ, practically no change is observed in the histologic structure of the walls. ${ }^{1}$ If the central end of an artery, e. g., the common carotid, be anastomosed to the peripheral end of a vein, e. g., the external jugular, the result is usually some alteration in the structure of both artery and vein, evidenced in the former by a decrease and in the latter by an increase in the thickness of the wall. ${ }^{2}$ In rapid transplantation of segments of blood vessels in animals of the same species, with only a short interval of anemia of the segment, ${ }^{3}$ as well as in heterotransplantations, ${ }^{4}$ marked histologic changes occur, as a rule, in the segments, be they arteries or veins. Ordinarily this consists of a dilatation of the lumen and a thickening of the wall. ${ }^{5}$

Even in the simpler operation of end-to-end anastomosis of artery to vein, two important factors must be considered in accounting for these changes, viz.: (a) alteration of the functional circulation, consisting of a change of pressure in the lumen of the vessel; and (b) alteration of the circulation in the nutritional capillaries, i. e., in the vasa vasorum.

In the case of rapid transplantation of a segment of blood ressel in the same animal three additional conditions must be considered, viz.: (c) complete abolition of the circulation in the nutritional capillaries; (d) complete abolition of the lymphatic circulation, and (e) complete severance of nervous connections; while in the case of isotransplantations or heterotransplantations still another factor must be added, (f) in the former the possible and in the latter the probable toxicity of the. host's body liquids for the segment. ${ }^{8}$

The transplantation of a segment of rabbit's aorta between the cut ends of a dog's common carotid artery may be taken as an illustration of the magnitude of the histologic changes that may occur, and yet the mechanical function of conveying blood remain adequate. Three weeks after the operation direct examination showed considerable enlargement and thickening of the segment." After eight months the enlargement, both in

1. Guthrle: Demonstration before Am. Physiol. Soc., Chicago, Dec. 31,1907 .

2. Carrel and Guthrie: Surg. Gyn. and Obst., 1906, 11, 3. 275.

3. Id., p. 281. Carrel : Jour. Fxp. Med., 1908, x, 1, 130.

4. Carrel : Jour. Exp. Med., 1007, ix, 2, 226. Guthrie : Am. Jour. Physiol., xix, 4, 482. Guthrie : Proc. Am. Physiol. Soc., 1907. 5. Id. Carrel : Jour. Exp. Med., 1908, x, 1, 130.

6. The view has been expressed by Carrel (Jour. Exp. Med. 1908, $x, 1,130$ ) that the escape of blood into the tissues is a probable factor in the change observed in the wall. In my own cases, this may be excluded, as complete hemostasis before closure of the wound is invariably practiced.

7. Guthrie: Proc. Am. Physiol. Soc., 1907. 